\title{
Vitamin D and aspects of female fertility
}

\author{
Nick Voulgaris, ${ }^{1}$ Labrini Papanastasiou, ${ }^{1}$ George Piaditis, ${ }^{1}$ Anna Angelousi, ${ }^{2}$ \\ Gregory Kaltsas, ${ }^{2}$ George Mastorakos, ${ }^{3}$ Eva Kassi ${ }^{4}$
}

${ }^{1}$ Department of Endocrinology and Diabetes Center, "G. Gennimatas", General Hospital of Athens, Athens Greece; 2Endocrine Unit, Department of Pathophysiology, National and Kapodistrian University of Athens, "Laiko" University Hospital, Athens, Greece; ${ }^{3}$ Endocrine Unit, 2nd Department of Obstetrics and Gynecology, National and Kapodistrian University of Athens, "Aretaieion" University Hospital, Athens, Greece; ${ }^{4}$ Department of Biological Chemistry, Medical School, National and Kapodistrian University of Athens, Athens, Greece

\begin{abstract}
The role of vitamin $D$ in female reproduction has been intensively examined over the last few decades. A large body of evidence suggests that vitamin $D$ might have beneficial effects on metabolic/hormonal parameters of PCOS and endometriosis, while it appears to be associated with IVF outcomes. However, due to the heterogeneity among observational and interventional studies, no cause-effect relationship has yet been established. The aim of this review is to analyze recent in vitro animal and human studies which examined the association of vitamin $D$ with disease entities affecting female fertility potential. Recent research data strongly imply that vitamin $D$ is implicated in female reproduction and might represent a beneficial and inexpensive therapeutic approach, in combination with first-line medical treatments, to female infertility.
\end{abstract}

Key words: Endometriosis, Female fertility, IVF, PCOS, Vitamin D

\section{INTRODUCTION}

Vitamin D is a secosteroid hormone mainly produced in the skin after sunlight exposure and is primarily known for its role in bone health and mineralization. ${ }^{1}$ In the last few years, the extraskeletal actions of vitamin D have emerged as a significant area of intensive scientific interest. The understanding that vitamin D receptor (VDR) and the enzymes required for the production of the active form of vitamin $\mathrm{D}$ are

\footnotetext{
Address for correspondence:

Eva Kassi, MD, Department of Biological Chemistry, Medical Scholl, National and Kapodistrian University of Athens, 75 Mikras Asias Str., P.C. 11527, Goudi, Athens, Greece; E-mail: ekassi@med.uoa.gr

Received: 07-11-2016, Accepted: 28-02-2017
}

expressed in almost all human cells and tissues has linked vitamin D insufficiency/deficiency to many chronic diseases such as cancer, autoimmune and infectious diseases as well as cardiovascular diseases and diabetes mellitus type 2. ${ }^{1,2}$ Vitamin D deficiency, defined as serum 25-hydroxyvitamin D levels of $<20 \mathrm{ng} / \mathrm{ml}$, is estimated to affect about $50 \%$ of the population worldwide. ${ }^{1}$

Infertility is a hot topic in the field of public health, affecting about 48.5 million couples worldwide ${ }^{3}$ with significant psychological, medical and economic consequences. PCOS and endometriosis comprise the main causes of female infertility, with in vitro fertilization (IVF) offering a solution to this problem. Data accruing from studies undertaken either in animals 
or humans point to a potential role of vitamin $\mathrm{D}$ in female fertility. ${ }^{4}$ In this context, epidemiological data have demonstrated a seasonality in human reproductive capacity, which could be partially explained by seasonal variation of vitamin D levels. ${ }^{5}$

The aim of this review is to critically assess current literature data regarding the role of vitamin D in IVF and its association with PCOS and endometriosis.

\section{METHODOLOGY}

We searched Pubmed for English language publications up to February 2017 under the following terms: "Vitamin D and female infertility" and "Vitamin D and female reproduction" and "Vitamin D and PCOS" and "Vitamin D and endometriosis", "Vitamin D and granulose cells" and "Vitamin D and IVF". We also used the terms 25-hydroxyvitamin D or $25(\mathrm{OH})$ vitamin D or 1,25-dihydroxyvitaminD or $1,25(\mathrm{OH})_{2} \mathrm{D}_{3}$ instead of Vitamin $\mathrm{D}$, and the term assisted reproduction technologies (ART) instead of IVF. Additionally, we included references on relevant topics from the reviewed articles in order to widen our search. Because a comprehensive background is a prerequisite for further discussions on vitamin D-induced effects, we provide a brief description of vitamin D metabolism and mechanism of action.

\section{VITAMIN D METABOLISM AND MECHANISM OF ACTION}

Vitamin D is a steroid hormone well known for its role in calcium homeostasis and bone mineralization. It is mainly produced in the skin after sunlight exposure. Diet and dietary supplements constitute alternative sources of vitamin D for humans. ${ }^{1}$ There are two distinct forms of vitamin $\mathrm{D}$, that of $\mathrm{D}_{2}$ or ergocalciferol and $\mathrm{D}_{3}$ or cholecalciferol. Cholecalciferol is formed in the human skin from 7-dehydrocholesterol (7-DHC), a cholesterol precursor, in the presence of ultraviolet $B$ radiation (UVB). UVB converts 7-DHC to previtamin $D_{3}$, which is rapidly isomerized to vitamin $\mathrm{D}_{3}$. Ergocalciferol derives from several nutritional sources including green plants, mushrooms, fish fat and cod liver oil. Another source of vitamin D is commercially available vitamin D supplements. ${ }^{6,7}$

Vitamin D, supplied either by UV irradiation of the skin or from the diet, is biologically inactive and requires two successive hydroxylations in the liver and in the kidneys by 25-hydroxylase (CYP27A1) and 1a-hydroxylase (CYP27B1) to produce its biologically active form, 1,25-dihydroxy-vitamin-D $\left[1,25(\mathrm{OH})_{2} \mathrm{D}_{3}\right]$ or calcitriol, respectively. ${ }^{1}$ It should be noted that the vitamin $\mathrm{D}$ status of the human body is best indicated by the circulating levels of $25(\mathrm{OH})$ VitD due to its longer half-life and higher serum concentration compared to $1,25(\mathrm{OH})_{2} \mathrm{D}_{3 .}{ }^{1}$ Calcitriol acts through binding to specific nuclear receptor, VDR, which upon activation initiates multiple genomic effects. Calcitriol may also bind to a plasma membrane receptor mediating several non-genomic effects. ${ }^{8}$ VDR acts in concert with the retinoid $X$ receptor (RXR), forming a heterodimer, as well as with other cofactors (repressors or activators) which regulate its function. ${ }^{9}$ The VDR-RXR heterodimer binds to vitamin $\mathrm{D}$ responsive elements (VDREs) located in the promoter region of target genes, thus regulating their transcription. ${ }^{8}$

The main action of vitamin $\mathrm{D}$ is the absorption of calcium and phosphate from the gut, this required for bone mineralization. ${ }^{1}$ However, the wide distribution of VDR in almost all human tissues and the fact that $3 \%$ of the human genome is regulated by the vitamin $\mathrm{D}$ endocrine system point to a potential extra-skeletal role of vitamin D in various systems and organs, among them reproduction. ${ }^{1,10}$

\section{In vitro studies}

\section{In animal cells}

VDR is expressed in the reproductive tissues (endometrium, ovaries and fallopian tubes) of cycling mice, especially during the estrous cycle, ${ }^{11}$ as well as in placenta, decidua and the ovaries of pregnant mice. ${ }^{12}$

Animal models have shown that vitamin D induces ovarian steroidogenesis. Vitamin D increased dehydroepiandrosterone sulfotranserase (SULT2A1) transcription, an enzyme that mediates sulfo-conjugation of endogenous hydroxysteroids. ${ }^{13}$ Moreover, calcitriol significantly decreased the expression of the antiMullerian hormone messenger RNA (AMH-mRNA) in hen granulosa cell cultures, whereas it increased the FSH receptor gene, indicating a positive role of vitamin $\mathrm{D}$ in follicular development and selection. ${ }^{14}$ 


\section{In human cells}

VDR is expressed in human ovarian tissue and placenta. ${ }^{15,16}$ In terms of ovarian steroidogenesis, human ovarian cells stimulated progesterone, estradiol and estrone production in the presence of calcitriol. ${ }^{16}$ Furthermore, human granulosa cells cultured with vitamin $\mathrm{D}_{3}$ increased $3 \beta$-HSD messenger (mRNA) levels and progesterone release. ${ }^{17}$ In line with animal models, in vitro experiments in human models showed that vitamin D induces dehydroepiandrosterone sulfotranserase (SULT2A1). ${ }^{13}$ Vitamin D is also associated with markers of ovarian reserve, especially with AMH. ${ }^{18}$ Interestingly, a subsequent study demonstrated that the human AMH promoter contains a functional VDRE. ${ }^{19}$ Finally, human granulosa cells treatment with vitamin $\mathrm{D}_{3}$ resulted in a significant decrease in AMHR-II and FSH receptor mRNA. ${ }^{17}$ Given the inhibitory effects of AMH on the development of human granulosa cells, the decrease of AMH expression after vitamin D treatment may reflect a beneficial effect of vitamin D in the differentiation of these cells.

In vitro studies on endometriosis have yielded limited data. One of them showed that treatment of human endometriotic stromal cells (ESCs) with calcitriol significantly suppresses the interleukin(IL)- $1 \beta$ and tumor necrosis factor-alpha (TNF- $\alpha$ ) induced inflammatory responses, mainly via reducing IL- 8 mRNA expression and prostaglandin activity; viable ESCs numbers were also reduced. These results illustrate a potential immunomodulatory role of vitamin $\mathrm{D}$ in the inflammatory process of endometriosis. ${ }^{20}$

With regard to IVF, an in vitro study ${ }^{21}$ investigated the immunomodulatory effect of vitamin $\mathrm{D}$ treatment on cytokine production [IL-6, IL-8, IL-10, transforming growth factor- $\beta$ (TGF- $\beta$ )] by endometrial cells of women with repeated implantation failure (RIF), the latter defined as three or more unsuccessful ART cycles after embryo transfer. ${ }^{22}$ Whole endometrial cells (WECs) and endometrial stromal cells (ESCs), obtained from RIF and normal fertile women, were treated with calcitriol. Endometrial cells from both the RIF group and the fertile group were capable of reducing cytokine production after calcitriol treatment, particularly IL-6 which facilitates the implantation process. On the other hand, WECs from both groups and ESCs only from the RIF group increased IL-8 and TGF- $\beta$ production, respectively, which could be beneficial for RIF women. Moreover, calcitriol downregulated the increased amounts of interferon $\gamma$ (IFN- $\gamma$ ) produced by unexplained recurrent spontaneous abortion (URSA) women, albeit increasing the secretion of TGF- $\beta{ }^{23}$ Interestingly, in both studies whole and stromal endometrial cells were able to produce the active form of vitamin D, since they express 1ahydroxylase. On the basis of these inconclusive data, the authors could not determine any clear effect of calcitriol on implantation, either positive or not, and highlighted the need for further research. ${ }^{21}$

It has also been shown that in the fetoplacental unit, calcitriol affects human chorionic gonadotropin (hCG) production by human synctiotrophoblasts ${ }^{24}$ and stimulates estradiol and progesterone synthesis by human placental cells. ${ }^{25}$ Meanwhile, the expression of human placental lactogen (hPL) was also reported to be regulated by calcitriol. ${ }^{26}$ In addition, human term placental trophoblasts were found to express calbindin-D28k (CaBP28k), which belongs to a large class of calcium binding proteins and might be associated with calcium transfer or cell development in human trophoblast. ${ }^{27}$ Moreover, a recent study showed a direct and beneficial effect of vitamin $\mathrm{D}$ on human extravillous trophoblast (EVT) invasion. Given that vitamin D deficiency is likely to increase the risk of pre-eclampsia and fetal growth restriction through inadequate EVT invasion, optimal vitamin D status could prevent these complications..$^{28}$ Finally, human endometrial stromal cells cultured with calcitriol increased HOXA10 gene expression, which is crucial for the embryo implantation process. ${ }^{29}$

Recent evidence from in vitro studies conducted in human and animal cells points to the functional role of the vitamin D endocrine system in the physiology of female reproduction. However, there are divergent results, possibly attributable to its two forms and several metabolites, the different concentrations of vitamin D used and to species-specific variations. Moreover, since various cell types are involved in the reproductive machinery and a local system mainly driven by 1a-hydroxylase activity is present in almost all of these cells responsible for the concentrations of the active metabolite at the tissue level, any relevant experimental data extracted from in vitro experiments must be interpreted with caution. 


\section{Animal studies}

Data from animal studies also provide evidence of a clear role of vitamin D, either direct or indirect, in female reproductive functions. Diet-induced vitamin $\mathrm{D}$ deficient female rats demonstrated a reduction in overall fertility by $75 \%$ compared to vitamin D replete ones. Vitamin D deficient rat litters had small size and impaired neonatal growth. The impaired fertility rates were attributed to decreased impregnation and to increased number of pregnancy complications. ${ }^{30}$

\section{VDR knockout mice (VDR $\left.{ }^{-/-}\right)$}

VDR knockout mice manifested, apart from impaired bone formation and growth retardation, uterine hypoplasia and impaired folliculogenesis. Impressively, estrogen administration increased uterine weight of the VDR mutant mice, indicating a potential role of VDR in estrogen signaling. ${ }^{31}$

Moreover, aromatase activity (the key enzyme in estrogen biosynthesis) and CYP19 gene (which encodes aromatase) expression were decreased in the ovaries of VDR null mutant mice (VDR ${ }^{-/}$). Biochemically, the $\mathrm{VDR}^{-/}$mice were hypocalcemic with elevated levels of FSH and LH indicative of hypergonadotropic hypogonadism. Calcium supplementation increased aromatase activity and CYP19 gene expression in the ovary but failed to correct the elevated gonadotropins. Despite the above endocrinological abnormalities some $\mathrm{VDR}^{-/-}$mice with normocalcemia were fertile. The authors concluded that vitamin D has a potential role in estrogen biosynthesis through maintenance of normocalcemia and a direct effect on the expression of the aromatase gene..$^{32}$ Interestingly, a study showed that $\mathrm{VDR}^{-/-}$mice fed a high or medium calcium diet maintain $100 \%$ fertility. ${ }^{33}$

\section{1-a hydroxylase knockout mice [1a(OH)ase-1-]}

1-a hydroxylase knockout $\left[1 \alpha(\mathrm{OH}) \mathrm{ase}^{-/}\right]$female mice develop infertility with decreased estrogen and progesterone levels, elevated gonadotropins (FSH and $\mathrm{LH}$ ), impaired follicular development, defective corpus luteum formation and uterine hypoplasia. ${ }^{34,35}$ Moreover, similarly to $\mathrm{VDR}^{-/}$mice, a high calcium diet given to $1 \alpha(\mathrm{OH})$ ase $^{-/-}$mice improved their fertility. ${ }^{34}$ These results indicate that infertility is a secondary result of hypocalcemia and not a direct effect of vitamin D due to the absence of VDR. However, an older study reported reduced reproductive capacity of vitamin $\mathrm{D}$ deficient female rats regardless of serum calcium concentration. Vitamin D or calcitriol supplementation restored fertility, suggesting a direct role of vitamin D on female infertility. ${ }^{36}$

As concerns endometriosis and animal studies, vitamin D treatment of surgically induced endometriosis in rat models resulted in regression of the endometrial implants. ${ }^{37,38}$ Moreover, the VDR agonist elocalcitrol inhibited the development of endometriosis in a mouse model. ${ }^{39}$

Interesting results emerged from a recent study on pregnant vitamin $\mathrm{D}$ deficient mice. According to their findings, maternal vitamin D deficiency is highly likely to contribute to the exposure of the developing fetus to higher glucocorticoid levels; this occurs through a reduction of placental $11 \beta$-HSD2 (11 $\beta$-Hydroxysteroid dehydrogenase type 2 ) gene expression coding for the enzyme responsible for glucocorticoid inactivation while inducing the expression of the fetal head gene GILZ (glucocorticoid-induced leucine zipper) mainly regulated by glucocorticoids. Of note, a high exposure to glucocorticoids during this crucial period might be associated with adverse longterm health outcomes (mainly cardiometabolic and psychiatric disorders). ${ }^{40}$

\section{Vitamin D and polycystic ovary syndrome (PCOS)}

Polycystic ovary syndrome (PCOS) is the most common endrocrinopathy and the leading cause of infertility among women of reproductive age. ${ }^{41,42}$ It is a syndrome with clinical and biochemical heterogeneity which affects about $6-10 \%$ of women worldwide.

\section{(a) Vitamin D and insulin resistance}

Accumulating evidence suggests that vitamin D is associated with various metabolic and reproductive features of PCOS and thus may be involved in the pathogenesis of the syndrome. It is noteworthy that hyperinsulinemia and IR have a central role in the pathogenesis of PCOS, affecting the severity of clinical features independently of the presence of obesity. The following potential mechanisms linking vitamin D with IR have been proposed: (i) vitamin D improves insulin action by upregulating the expression of the insulin receptor and enhancing insulin responsiveness for glucose transport, ${ }^{43}$ (ii) $1,25(\mathrm{OH})_{2} \mathrm{D}_{3}$ activates the 
transcription of the VDRE of the human insulin gene which it has in its promoter; ${ }^{45}$ (iii) vitamin $\mathrm{D}$ regulates intracellular and extracellular calcium, which is crucial for insulin-mediated actions in insulin-responsive tissues; ${ }^{43}$ (iv) vitamin D exerts anti-inflammatory actions. ${ }^{2,9}$ However, most PCOS women are either overweight or obese. Obesity is associated with lower $25(\mathrm{OH})$ VitD levels, mainly due to the sequestration of the lipophilic vitamin in adipose tissue as well as due to lower sunlight exposure of obese subjects. These data raise the crucial question: Is vitamin D deficiency an additional risk factor aggravating IR in PCOS irrespectively of obesity? The following data attempt to address this issue.

\section{(b) VDR gene polymorphisms and PCOS}

The role of VDR in the regulation of the human genome has motivated researchers to examine the contribution of the $V D R$ gene polymorphisms in metabolic and endocrine disturbances of PCOS. The results reflect an influence of $V D R$ gene variants in PCOS features; however, because they are as yet controversial, it is difficult to establish a clear association of VDR polymorphisms with the development of PCOS.

VDR $A p a I^{46,47}$ and $B s m I$ gene ${ }^{47}$ polymorphisms were associated with an increased risk of PCOS, after adjustment of results for age and body mass index (BMI). By contrast, other studies failed to find any association of these variants with PCOS susceptibility. In a recent case-control study, $V D R$ gene polymorphisms (TaqI, ApaI, BsmI, FokI) were not associated with the classic PCOS phenotype in Silesian women. ${ }^{48}$ An Indian case-control study also failed to show any significant association between $V D R$ gene variants and PCOS. However, $C d x 2$ and FokI variants were associated with testosterone levels and infertility, respectively. ${ }^{49}$ The association between the VDR gene rs757343 polymorphism and PCOS risk was examined in two studies, but both failed to observe any link. ${ }^{50,51}$

One study reported an association of the VDR ApaI gene polymorphism with testosterone levels in PCOS women, whereas VDR $C d x 2$ variants were associated with insulin sensitivity. ${ }^{52}$ VDR BsmI and VDR TaqI gene polymorphisms were also associated with low SHBG levels and elevated LH levels, respectively. ${ }^{53}$

\section{(c) Observational studies}

Numerous observational studies investigated the association of $25(\mathrm{OH})$ VitD status with metabolic and endocrine parameters of PCOS (Table 1). In general, PCOS women had lower 25(OH)VitD levels compared to healthy controls. Among the PCOS population, obese women exhibited lower 25(OH)VitD levels than overweight or lean subjects.

\section{i) $25(\mathrm{OH})$ VitD status and metabolic markers}

The potential effects of PCOS and obesity on PTH, vitamin D metabolites and metabolic aspects of the syndrome were investigated in a study of 291 PCOS women and 109 controls. Serum 25(OH)VitD levels were lower in controls compared to PCOS women, while increased body weight had a negative effect on vitamin D status. Moreover, 25(OH)VitD serum levels were inversely correlated with body mass index (BMI), PTH, insulin levels and the homeostasis model assessment of insulin resistance index (HOMA-IR), although these differences were BMI dependent. ${ }^{54}$ Additionally, another study reported that PCOS women had higher levels of $25(\mathrm{OH}) \mathrm{VitD}$ than controls, although after adjustment for age and BMI the significance was almost abolished. ${ }^{55}$ In line with the previous results, 25(OH)VitD levels were found to be higher in PCOS women than in controls. In the latter study, the quantitative insulin sensitivity check index (QUICKI) was used as a surrogate index of IR. Interestingly, PCOS subjects had lower QUICKI than controls at any concentration of $25(\mathrm{OH}) \mathrm{VitD} .{ }^{56}$

In contrast with the aforementioned findings, one study failed to confirm any difference in $25(\mathrm{OH}) \mathrm{VitD}$ levels between PCOS patients $(n=37)$ and the control $(n=70)$ group. However, the investigated population were adolescent females and only $13 \%$ of them were vitamin D sufficient ( $>30 \mathrm{ng} / \mathrm{ml}$ ), which could have biased the results. ${ }^{57}$

On the other hand, a recent study conducted in Australia showed that vitamin D levels were lower in overweight PCOS women than in overweight controls $(31.6 \pm 11.3$ versus $46.1 \pm 20.0 \mathrm{nmol} / \mathrm{L})$, and this difference remained significant after adjustment for BMI and abdominal visceral fat. The hyperinsulinemic euglycemic clamp (HEC), the gold standard for the evaluation of insulin sensitivity, was used to evaluate 


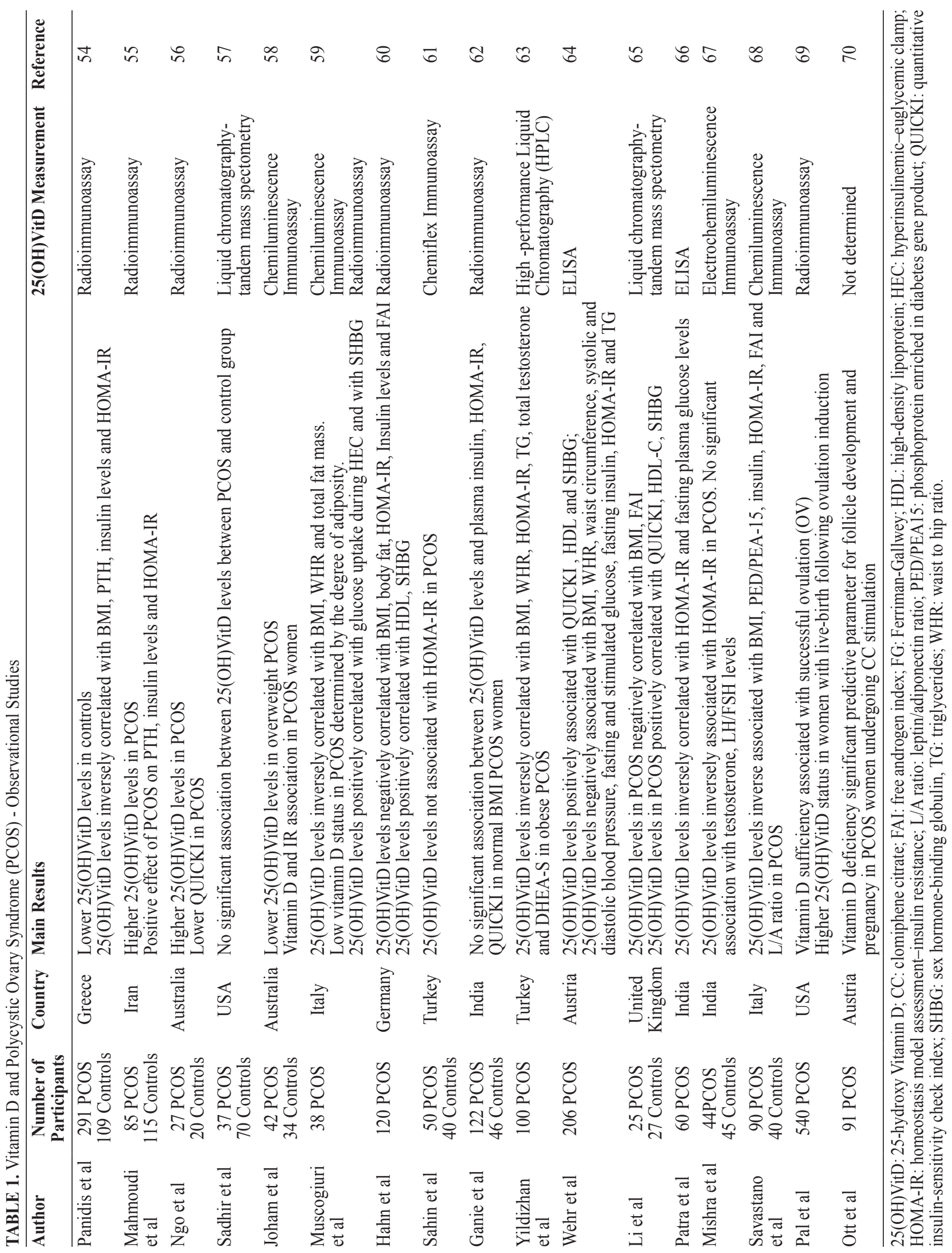


IR. Vitamin D was correlated with IR only in women with PCOS, but not in the non-PCOS group..$^{58}$

The gold standard technique of HEC was also used in a study of 38 PCOS women, $37 \%$ of whom were reported to be vitamin D deficient $(25(\mathrm{OH}) \mathrm{VitD}$ levels $<50 \mathrm{nmol} / \mathrm{L})$. In this study, 25(OH)VitD levels were inversely correlated with BMI, waist to hip ratio and total fat mass but were positively correlated with glucose uptake during HEC. Moreover, total fat mass of these PCOS subjects, estimated by dual-energy $\mathrm{X}$-ray absorptiometry (DEXA), was an independent predictor of $25(\mathrm{OH}) \mathrm{VitD}$ levels, indicating that low vitamin D status in PCOS is determined by the degree of adiposity and is unrelated to PCOS. However, the absence of a control group in this study limits its potential. ${ }^{59} \mathrm{~A}$ high prevalence $(67.5 \%)$ of vitamin $\mathrm{D}$ deficiency [25(OH)VitD $<20 \mathrm{ng} / \mathrm{ml}$ ] was observed among 120 PCOS women (lean $=32$, overweight $=18$, obese=70). Furthermore, vitamin D levels were (i) negatively correlated with BMI, body fat, HOMAIR and insulin levels, and (ii) positively correlated with HDL. In agreement with the previous study, the inverse relationship between $25(\mathrm{OH}) \mathrm{VitD}$ levels and obesity was irrelevant to PCOS. ${ }^{60}$ Likewise, vitamin D status was not correlated with HOMA-IR in normal BMI $\left(<25 \mathrm{~kg} / \mathrm{m}^{2}\right)$ PCOS women. ${ }^{61,62}$ Several studies demonstrated an inverse correlation of BMI, body fat and HOMA-IR with serum 25(OH)VitD levels. ${ }^{63-66}$ Recently, a study found an inverse association of 25(OH)VitD levels with HOMA-IR but not with BMI, while PCOS subjects exhibited marked dyslipidemia. ${ }^{67}$

\section{ii) $25(\mathrm{OH})$ VitD status and hyperandrogenism markers}

In a study of 120 PCOS women (median age 28 years), 25(OH)VitD levels were significantly correlated with free androgen index (FAI) and SHBG but not with testosterone, DHEA-S, androstendione and $\mathrm{LH} / \mathrm{FSH}$ ratio. ${ }^{60}$ In subsequent studies $25(\mathrm{OH}) \mathrm{VitD}$ levels were positively associated with $\mathrm{SHBG}^{64,65}$ and negatively associated with FAI. ${ }^{65}$

On the other hand, a study of 100 PCOS women demonstrated that $25(\mathrm{OH})$ VitD levels were negatively correlated with testosterone and DHEA-S levels in obese PCOS subjects. ${ }^{63}$ However, a recent study failed to observe any association between $25(\mathrm{OH})$ VitD levels and hyperandrogenism markers. ${ }^{67}$
Interestingly, low 25(OH)VitD levels in PCOS women was associated with higher levels of an antiapoptotic protein, phosphoprotein enriched in diabetes gene product (PED/PEA-15) ${ }^{68}$ This inverse association could account for the dysregulated ovarian apoptosis seen in PCOS women.

A recent retrospective cohort study reported that PCOS infertile women with adequate $25(\mathrm{OH}) \mathrm{VitD}$ levels $(>30 \mathrm{ng} / \mathrm{ml})$ were more likely to achieve ovulation compared to those with 25(OH)VitD levels $<20$ $\mathrm{ng} / \mathrm{ml}$. Moreover, women achieving live births had higher 25(OH)VitD levels compared to those failing to carry out a live birth. Thus, an adequate $25(\mathrm{OH})$ VitD status could be a determining factor for a successful ovulation and pregnancy outcome for infertile PCOS women. ${ }^{69}$

Finally, a prospective cohort study assessed reproductive parameters of PCOS and found that $25(\mathrm{OH})$ VitD deficiency $(<25 \mathrm{nmol} / \mathrm{L})$ was a significant predictive parameter for both follicle development and pregnancy in anovulatory infertile PCOS women who underwent clomiphene citrate (CC) stimulation. ${ }^{70}$

The heterogeneity of the studies could be explained by the variety of methodologies used for the assessment of VitD, the heterogeneity of study populations (small study samples, absence of control group) and the lack of adjustement for confounders, such as seasonality of $25(\mathrm{OH})$ VitD.

It could be concluded that the existing data converge towards a high prevalence of vitamin D deficiency among PCOS women and an inverse association with insulin sensitivity markers. However, the exact interrelationship between vitamin D status, obesity, IR and hyperandrogenism in PCOS still remains unclear and warrants further research.

\section{(d) Interventional studies and PCOS}

A notable number of interventional studies (Table 2) explored the therapeutic implications of vitamin $D$ in the metabolic and reproductive aspects of PCOS. ${ }^{71-84}$ Meanwhile, recent meta-analyses of supplementation studies could not support a therapeutic effect of vitamin D treatment on metabolic disorders of the syndrome, ${ }^{85-87}$ apart from its positive effect on the reduction of serum triglycerides. ${ }^{88}$ In terms of hyperandrogenism markers, one meta-analysis con- 
cluded that vitamin D treatment could improve follicle development and menstrual cyclicity, especially in combination with metformin, ${ }^{87}$ whereas the other found no beneficial effect. ${ }^{85}$

Interestingly, recent studies indicate new potential pathways via which vitamin $\mathrm{D}$ could be implicated in the pathogenesis of PCOS. More specifically, advanced glycation end-products (AGEs) are involved in the pathological process of PCOS..$^{89,90}$ The interaction of AGEs with their receptor (AGE-RAGE) induces pro-inflammatory gene activation resulting in cellular damage. ${ }^{91}$ These adverse effects are counteracted by an extracellular form of RAGE, the soluble receptor for AGEs (sRAGE), which binds to circulating AGEs, thereby inhibiting AGE-RAGE interaction. Based on the above data, 16 PCOS women and 35 controls were treated with vitamin $\mathrm{D}_{3}$ for 8 weeks. The improvement in vitamin D status of PCOS women was associated with a significant increase in SRAGE, indicating that vitamin D could exert anti-inflammatory actions by increasing sRAGE levels..$^{92}$ Moreover, serum AMH levels in PCOS patients were reduced, thus vitamin $\mathrm{D}_{3}$ supplementation might improve ovary dysfunction and folliculogenesis in these women via normalization of AMH levels. ${ }^{92}$

Apart from AGEs, TGF- $\beta$ dysregulation may possibly be im plicated in the pathophysiology of PCOS, given its role in angiogenesis, fibroblast activation and tissue fibrosis, which could explain morphological and vascular alterations of PCOS ovaries.$^{93}$ PCOS women display an abnormal increase in TGF- $\beta 1$ bioavailability, which is mainly attributed to the decreased levels of soluble endoglin (sENG), a circulating receptor that binds TGF- $\beta 1 .{ }^{94,95}$

Recently, a study examined possible effects of vitamin $\mathrm{D}$ administration on TGF- $\beta 1$ bioavailability in vitamin D deficient PCOS women. Vitamin D supplementation significantly increased serum sENG and decreased TGF- $\beta 1$ bioavailability (TGF- $\beta 1 / \mathrm{sENG}$ ). Moreover, vitamin D replacement decreased serum triglycerides, the Ferriman-Gallwey score and the menstrual interval. Further, the decrease in TGF- $\beta 1$ bioavailability ( $\triangle$ TGF- $\beta 1 /$ sENG ratio) was associated with an improvement in lipid profile. These findings suggest that vitamin D induced decrease in TGF- $\beta 1$ bioavailability in PCOS subjects might be a novel mechanism through which vitamin $\mathrm{D}$ exerts its beneficial effects on certain aspects of PCOS. ${ }^{93}$

In conclusion, despite the abundance of existing literature data regarding supplementation studies, their results are inconsistent and no clear conclusion can be drawn about the effect of vitamin D administration on metabolic and reproductive parameters of PCOS. The aforementioned intervention studies are subject to several limitations, which partially explain the lack of apparent concordance. Firstly, some of them include a small sample size and/or lack randomization and allocation concealment, hence increasing the risk of selection bias. There is substantial heterogeneity with respect to 25(OH)VitD status of patients at baseline, the methodology used for 25(OH)VitD assessment, dosing regimen and intervention formulations, duration, use of concomitant therapies, all of which could contribute to the discrepancy of the observed results. Furthermore, these studies were conducted in different countries and at different seasons, factors which could also influence the results. In fact, lack of adjustment for confounders such as the seasonality of $25(\mathrm{OH})$ VitD or even the existence of residual confounders are significant shortcomings in the studies conducted. The use of a single baseline vitamin D measurement which may not reflect longterm vitamin $\mathrm{D}$ status could also affect the validity of the interventional studies. ${ }^{96}$ Moreover, the ultrasound criteria of diagnosis of PCOS and of the definition of ovulatory cycles varies among studies this also conducing to the low quality of many of them.

\section{Vitamin $D$ and endometriosis}

Endometriosis is a common benign inflammatory disorder that affects 5 to $10 \%$ of women of reproductive age, the main clinical features including pelvic pain, dysmenorrhea, dyspareunia and infertility. ${ }^{97}$ The pathogenesis of endometriosis has not been well established, but it seems that an altered immune and inflammatory response enables the survival of endometrial implants. ${ }^{97}$

The association between vitamin $\mathrm{D}$ and endometriosis is based on the following findings: 1) the human endometrium expresses VDR and 1a-hydroxylase, thus it could be a possible site of extrarenal synthesis and action of vitamin $\mathrm{D} ;{ }^{98} 2$ ) vitamin $\mathrm{D}$ has immunomodulatory effects; macrophages, dendritic 


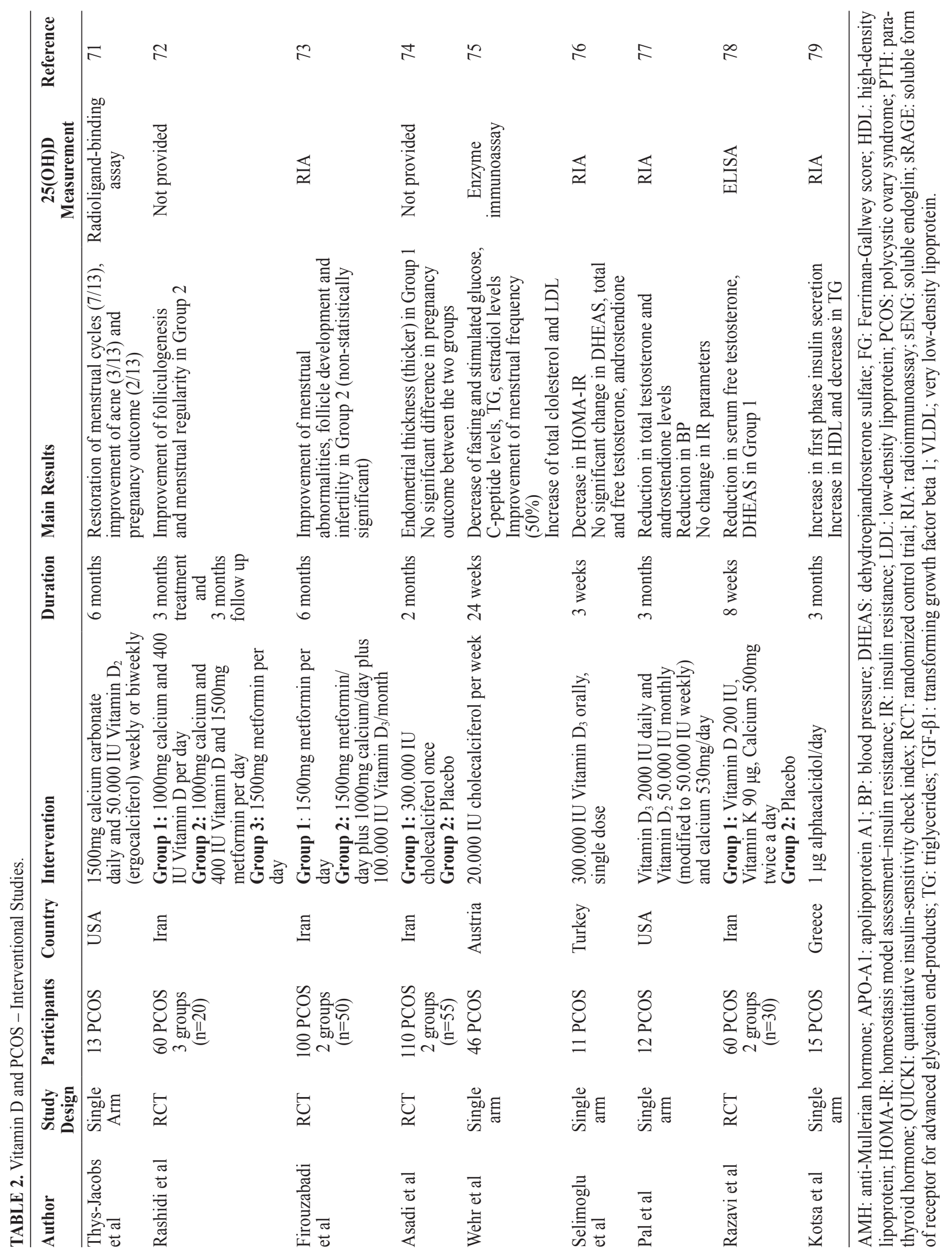




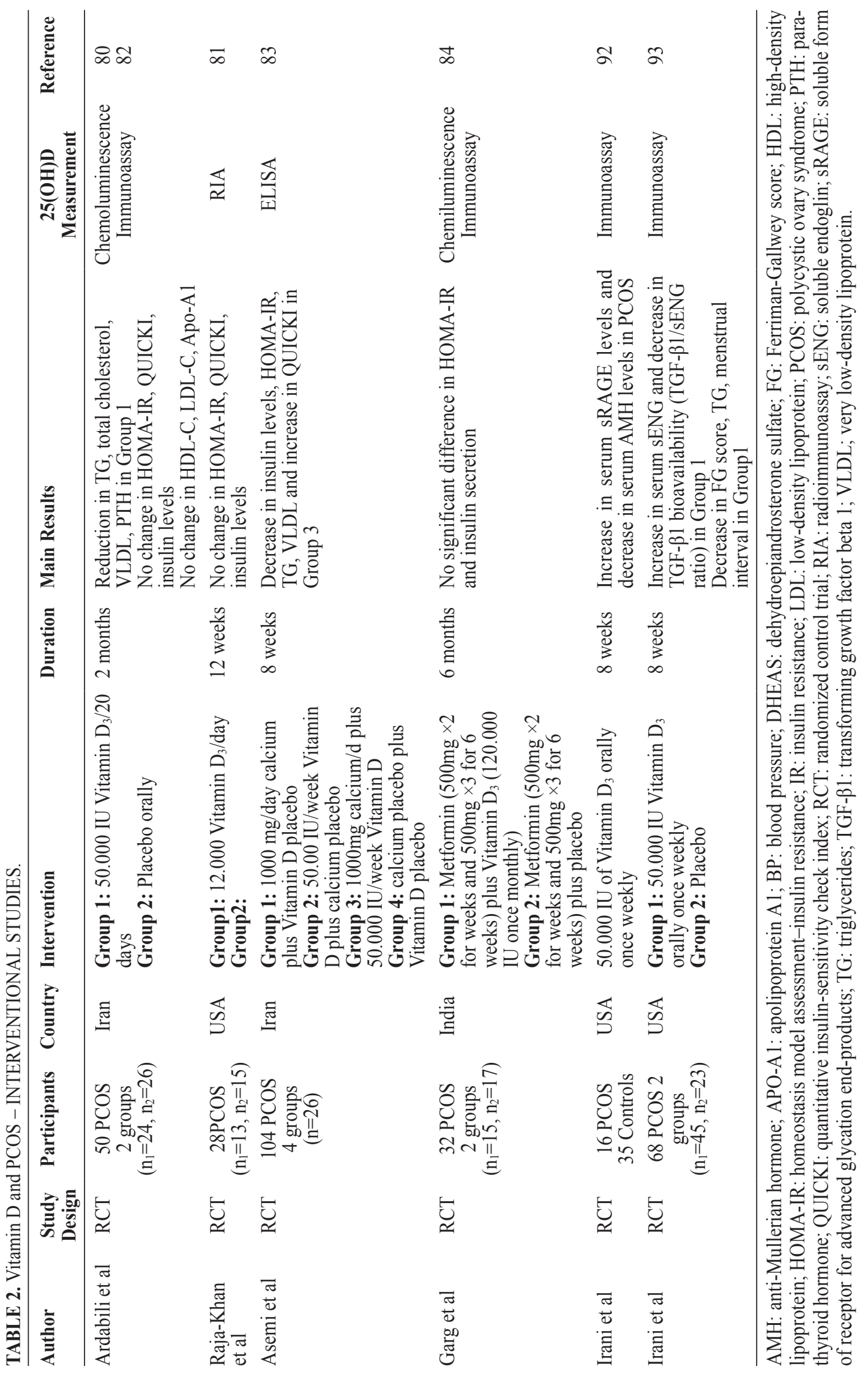


cells and lymphocytes express the VDR, while the active metabolite of vitamin $\mathrm{D}, 1,25(\mathrm{OH})_{2} \mathrm{D}_{3}$ acting through the VDR was found to induce the destruction of microbial agents and to inhibit antigen presentation and maturation of dendritic cells. Moreover, vitamin D exerts antiproliferative effects on lymphocytes, especially on Th1 cells, promoting a shift from Th1 to Th2 phenotype. . $^{1,2,9}$

Data linking vitamin D and endometriosis emerge mainly from observational studies and show conflicting results. Several studies failed to note any difference between serum $25(\mathrm{OH})$ VitD levels in patients with endometriosis and healthy subjects..$^{99,100}$ However, VDR and 1a-hydroxylase expression was higher in the endometrium and ovaries of women with endometriosis compared to healthy subjects, although this difference was statistically significant only for 1a-hydroxylase, implying a higher local production of the active metabolite calcitriol and/or an increased action of vitamin D. ${ }^{100}$

On the other hand, recently published data show an inverse relationship between vitamin D level and endometriosis, as women with greater $25(\mathrm{OH}) \mathrm{VitD}$ level had a $24 \%$ lower risk of developing endometriosis than women with lower levels. ${ }^{101}$ What is more, in this large prospective cohort study the researchers found that higher consumption of dairy foods was associated with a lower risk of endometriosis. Similarly, a Japanese study reported lower 25(OH)VitD levels in women with severe endometriosis compared to controls and women with mild endometriosis. ${ }^{20}$ Recently, an observational study found a high rate of hypovitaminosis D $[25(\mathrm{OH})$ VitD serum level $<30$ $\mathrm{ng} / \mathrm{ml}$ ] in a cohort of 49 women with a single ovarian endometrioma. ${ }^{102}$

In contrast, significantly higher levels of $25(\mathrm{OH})$ VitD were observed in the serum of women with endometriosis compared to healthy individuals $(24.9 \pm 14.8$ $\mathrm{ng} / \mathrm{ml}$ vs $20.4 \pm 11.8 \mathrm{ng} / \mathrm{ml}) .{ }^{103}$

Additionally, VDBP in serum, peritoneal fluid (PF) and urine was examined as a possible biomarker of endometriosis. A study using proteomic technologies for VDBP analysis demonstrated its presence in the PF of women with endometriosis, whereas one vitamin D binding protein (DBP) isoform (DBPE) was expressed to a lower degree in the PF of women with untreated endometriosis compared to the control group. ${ }^{104}$

However, another study found no difference between serum and peritoneal fluid levels of VDBP of women with endometriosis compared to the control group. ${ }^{105}$ VDBP levels were also evaluated in urine samples of women with endometriosis and found to be significantly higher in women with endometriosis, albeit the sensitivity (58\%) and specificity (76\%) of this method limits its diagnostic value. ${ }^{106}$ Moreover, it has been shown that VDBP expression is significantly higher in ectopic endometrial tissue in comparison with the normal endometrium, suggesting a plausible local role of VDBP in the progression of the disease. ${ }^{107}$

Finally, in a cross-sectional study, VDBP was increased in all samples of women suffering from endometriosis compared to the control group. ${ }^{108}$ Interestingly, a subsequent analysis of the samples identified a specific allele of VDBP (GC*2) to be about 3 -fold higher in all endometriosis groups than in the control group. This specific VDBP polymorphism (high expression of $\mathrm{GC}^{*} 2$ ) could be responsible for an insufficient activation of macrophages leading to an altered immune response, which enables the development of endometriosis. ${ }^{108}$ The role of VDR gene polymorphisms (ApaI, TaqI, FokI, BmsI) in the pathogenesis of endometriosis and infertility associated with the disease has been studied but no association has been identified. ${ }^{109}$

Taken together, these data may indicate a plausible implication of vitamin D in the pathogenesis of endometriosis through exerting an autocrine/paracrine role in the endometrial microenvironment; however, further research is needed to determine whether vitamin D supplementation could have a role as an adjuvant therapy in the treatment of endometriosis or is merely a confounding factor.

\section{Vitamin D and in vitro fertilization (IVF)}

The implication of Vitamin D in the outcome of ART (clinical pregnancy and live birth) has been examined in numerous studies. Nevertheless, the data are inconsistent and a clear role of vitamin $\mathrm{D}$ in the success of IVF outcome remains elusive.

In the first experimental attempt to link vitamin D status with IVF outcome, vitamin D sufficient women undergoing IVF had higher pregnancy and implan- 
tation rates compared with the vitamin $\mathrm{D}$ deficient women. ${ }^{110}$ The beneficial impact of high vitamin D status on IVF outcome could be attributed to the effects of vitamin D on the endometrium, since vitamin D status was not significantly associated with ovarian response parameters.

In line with the previous study, a retrospectivecohort study found a positive relationship between vitamin D status and IVF success only in non-Hispanic whites compared to Asians, indicating that the role of vitamin D in IVF should be evaluated in relation to ethnic origin. Furthermore, it was also hypothesized that the positive effects of vitamin D on ART outcome may be mediated through endometrial pathways. ${ }^{111}$

In order to test this hypothesis, a subsequent study investigated the influences of vitamin D status on ART outcomes in donor-recipient cycles. ${ }^{112}$ Egg-donation recipients with non-replete vitamin D status $[25(\mathrm{OH})$ VitD $<30 \mathrm{ng} / \mathrm{ml}$ ] had reduced clinical pregnancy and live birth rates. Moreover, no correlation between recipient vitamin D status and ovarian stimulation parameters, fertilization rates, embryo quality or the number of embryos transferred was noted, suggesting that vitamin D appears to exert its effects on fertility via the endometrium. However, donor characteristics were not included in the latter study, which could confound these results.

The majority of the following studies demonstrated a positive relationship between higher vitamin D status and IVF outcome. ${ }^{113-115}$ Recent data imply that vitamin D deficiency $(<20 \mathrm{ng} / \mathrm{ml})$ compromises pregnancy achievement in women undergoing Day 5 (blastocyst stage) single embryo transfer (SET). The lower clinical pregnancy rates were attributed to a harmful effect of vitamin D deficiency on endometrial receptivity. ${ }^{116}$

Conversely, a prospective observational study found that elevated follicular fluid (FF) 25(OH)VitD levels in combination with decreased FF glucose levels were associated with poorer embryo quality and negative IVF outcome, indicating a potential negative role of vitamin $\mathrm{D}$ at the oocyte level. ${ }^{117}$ However, the above observation is in contrast to the detrimental effects of vitamin $\mathrm{D}$ deficiency on the endometrium reported in previous studies. ${ }^{110-112,116}$ Additionally, two Iranian studies ${ }^{118,119}$ failed to demonstrate any significant association between serum or FF vitamin D levels and implantation or pregnancy rates. However, the high prevalence of vitamin D deficiency in the examined population limits the strength of their research.

Furthermore, vitamin D status was not associated with clinical pregnancy rates of women undergoing euploid embryo transfer, ${ }^{120}$ frozen-thawed embryo transfer ${ }^{121}$ and clinical pregnancy rates among oocyte recipients. ${ }^{122}$ An interventional trial examined potential effects of vitamin D insufficiency treatment on fertility outcomes regarding frozen-thawed embryo transfer cycles but did not show any association. ${ }^{123}$ Finally, a recent meta-analysis failed to document any correlation between vitamin D deficiency and pregnancy rates in women undergoing IVF. ${ }^{124}$ The heterogeneity among the aforementioned studies and their contradictory results highlight the need for further research so as to clarify the exact association of vitamin D status and IVF success.

\section{Vitamin D status and female fertility}

Endocrine Task Force guidelines define vitamin D deficiency as a $25(\mathrm{OH})$ VitD level of $<20 \mathrm{ng} / \mathrm{ml}$, vitamin D insufficiency as a $25(\mathrm{OH})$ VitD level of $21-29 \mathrm{ng} / \mathrm{ml}$ and vitamin D sufficiency as a $25(\mathrm{OH})$ VitD level of $\geq 30 \mathrm{ng} / \mathrm{ml} .{ }^{125}$ The Institute of Medicine Committee defines vitamin D deficiency at a level below $20 \mathrm{ng} / \mathrm{ml} .{ }^{126}$ These definitions however are related only to skeletal health and an optimal level of vitamin D levels for its non-skeletal actions has not been established. Of interest, according to the Endocrine Society Task Force, vitamin $\mathrm{D}_{2}$ or vitamin $\mathrm{D}_{3}$ are the suggested treatment options for vitamin $\mathrm{D}$ deficiency. On the other hand, literature data indicate that vitamin $\mathrm{D}_{3}$ is more effective in increasing $25(\mathrm{OH})$ VitD levels than vitamin $\mathrm{D}_{2} \cdot{ }^{127-130}$ Clearly, the optimal level of vitamin D in female fertility and the type of supplements required for the treatment of vitamin $\mathrm{D}$ deficiency are two significant issues which merit further research and need to be addressed.

\section{CONCLUSION}

There are a large number of in vitro, animal as well as human observational studies which strongly point towards an association between vitamin $\mathrm{D}$ and female fertility. Research data indicate that vitamin $\mathrm{D}$ might be implicated in the pathogenesis and prevention of endometriosis, while vitamin D status has 
been linked to IVF outcome. Furthermore, vitamin D supplementation in PCOS women ameliorated some of the metabolic and, mainly, the reproductive disorders. Although promising, these data are not sufficient to establish a cause-effect relationship between vitamin D status and fertility issues. Moreover, there is still no general consensus as to the minimum level of vitamin D optimal for female reproductive health and fertility, while the screening of vitamin D status in women undergoing IVF is still under debate. Vitamin D administration is a well-tolerated and inexpensive treatment. However, whether vitamin D supplementation could be a novel adjunct agent in the treatment of metabolic/hormonal aspects of PCOS and endometriosis is a question still awaiting an answer. Large-scale, high quality dose-response RCTs with longer follow-up are needed 1) to determine the exact role of vitamin D in female IVF outcome, evaluated by indices such as the number of oocytes retrieved, the number and the quality of the embryo formed, the clinical pregnancy rates as well as the live birth rates and 2) to identify threshold effects of vitamin D supplementation on hormonal, metabolic and reproductive outcomes in PCOS.

\section{REFERENCES}

1. Holick MF, 2007 Vitamin D deficiency. N Engl J Med 357: 266-281.

2. Kassi E, Adamopoulos C, Basdra EK, Papavassiliou AG, 2013 Role of vitamin D in atherosclerosis. Circulation 128: 2517-2531.

3. Mascarenhas MN, Flaxman SR, Boerma T, Vanderpoel S, Stevens GA, 2012 National, regional, and global trends in infertility prevalence since 1990: a systematic analysis of 277 health surveys. PLoS Med 9: e1001356.

4. Anagnostis P, Karras S, Goulis DG, 2013 Vitamin D in human reproduction: a narrative review. Int $\mathrm{J}$ Clin Pract 67: 225-235.

5. Rojansky N, Brzezinski A, Schenker JG, 1992 Seasonality in human reproduction: an update. Hum Reprod 7: 735-745.

6. Holick MF, Chen TC, 2008 Vitamin D deficiency: a worldwide problem with health consequences. Am J Clin Nutr 87:1080s-1086s.

7. Holick MF, 2008 The vitamin D deficiency pandemic and consequences for nonskeletal health: mechanisms of action. Mol Aspects Med 29: 361-368.

8. Haussler MR, Jurutka PW, Mizwicki M, Norman AW, 2011 Vitamin D receptor (VDR)-mediated actions of 1alpha, 25(OH)(2)vitamin $\mathrm{D}(3)$ : genomic and nongenomic mechanisms. Best Pract \& Res Clin Endocrinol
Metab 25: 543-559.

9. Rosen CJ, Adams JS, Bikle DD, et al, 2012 The nonskeletal effects of vitamin D: an Endocrine Society scientific statement. Endocr Rev 33: 456-492.

10. Bouillon R, Carmeliet G, Verlinden L, et al, 2008 Vitamin D and human health: lessons from vitamin D receptor null mice. Endocr Rev 29: 726-776.

11. Zarnani AH, Shahbazi M, Salek-Moghaddam A, et al, 2010 Vitamin D3 receptor is expressed in the endometrium of cycling mice throughout the estrous cycle. Fertil Steril 93: 2738-2743.

12. Shahbazi M, Jeddi-Tehrani M, Zareie M, et al, 2011 Expression profiling of vitamin $\mathrm{D}$ receptor in placenta, decidua and ovary of pregnant mice. Placenta 32: 657664.

13. Echchgadda I, Song CS, Roy AK, Chatterjee B, 2004 Dehydroepiandrosterone sulfotransferase is a target for transcriptional induction by the vitamin $\mathrm{D}$ receptor. Mol Pharmacol 65: 720-729.

14. Wojtusik J, Johnson PA, 2012 Vitamin D regulates anti-Mullerian hormone expression in granulosa cells of the hen. Biol Reprod 86: 91.

15. Avila E, Diaz L, Halhali A, Larrea F, 2004 Regulation of 25-hydroxyvitamin D3 1alpha-hydroxylase, 1,25-dihydroxyvitamin D3 24-hydroxylase and vitamin D receptor gene expression by 8-bromo cyclic AMP in cultured human syncytiotrophoblast cells. J Steroid Biochem Mol Biol 89-90: 115-119.

16. Parikh G, Varadinova M, Suwandhi P, Araki T, Rosenwaks Z, Seto-Young D, 2010 Vitamin D regulates steroidogenesis and insulin-like growth factor binding protein-1 (IGFBP-1) production in human ovarian cells. Horm Metab Res 42: 754-757.

17. Merhi Z, Doswell A, Krebs K, Cipolla M, 2014 Vitamin $\mathrm{D}$ alters genes involved in follicular development and steroidogenesis in human cumulus granulosa cells. J Clin Endocrinol Metab 99: E1137-1145.

18. Broekmans FJ, Visser JA, Laven JS, Broer SL, Themmen AP, Fauser BC, 2008 Anti-Mullerian hormone and ovarian dysfunction. Trends Endocrinol Metab 19: 340-347

19. Malloy PJ, Peng L, Wang J, Feldman D, 2009 Interaction of the vitamin $\mathrm{D}$ receptor with a vitamin $\mathrm{D}$ response element in the Mullerian-inhibiting substance (MIS) promoter: regulation of MIS expression by calcitriol in prostate cancer cells. Endocrinology 150: 1580-1587.

20. Miyashita M, Koga K, Izumi G, et al, 2016 Effects of 1,25-Dihydroxy Vitamin D3 on Endometriosis. J Clin Endocrinol Metab 101: 2371-2379.

21. Rajaei S, Mirahmadian M, Jeddi-Tehrani M, et al, 2012 Effect of 1,25(OH)2 vitamin D3 on cytokine production by endometrial cells of women with repeated implantation failure. Gynecol Endocrinol 28: 906-911.

22. Levi Setti PE, Colombo GV, Savasi V, Bulletti C, Albani E, Ferrazzi E, 2004 Implantation failure in assisted reproduction technology and a critical approach 
to treatment. Ann N Y Acad Sci 1034: 184-199.

23. Tavakoli M, Jeddi-Tehrani M, Salek-Moghaddam A, et al, 2011 Effects of 1,25(OH)2 vitamin D3 on cytokine production by endometrial cells of women with recurrent spontaneous abortion. Fertil Steril 96: 751-757.

24. Barrera D, Avila E, Hernandez G, et al, 2008 Calcitriol affects hCG gene transcription in cultured human syncytiotrophoblasts. Reprod Biol Endocrinol 6: 3.

25. Barrera D, Avila E, Hernandez G, et al, 2007 Estradiol and progesterone synthesis in human placenta is stimulated by calcitriol. J Steroid Biochem Mol Biol 103: 529-532.

26. Tuan RS, Moore CJ, Brittingham JW, Kirwin JJ, Akins RE, Wong M, 1991 In vitro study of placental trophoblast calcium uptake using JEG-3 human choriocarcinoma cells. J Cell Sci 98: 333-342.

27. Belkacemi L, Gariepy G, Mounier C, Simoneau L, Lafond J, 2003 Expression of calbindin-D28k (CaBP28k) in trophoblasts from human term placenta. Biol Reprod 68: 1943-1950.

28. Chan SY, Susarla R, Canovas D, et al, 2015 Vitamin $\mathrm{D}$ promotes human extravillous trophoblast invasion in vitro. Placenta 36: 403-409.

29. Du H, Daftary GS, Lalwani SI, Taylor HS, 2005 Direct regulation of HOXA10 by $1,25-(\mathrm{OH}) 2 \mathrm{D} 3$ in human myelomonocytic cells and human endometrial stromal cells. Mol Endocrinol 19: 2222-2233.

30. Halloran BP, DeLuca HF, 1980 Effect of vitamin D deficiency on fertility and reproductive capacity in the female rat. J Nutr 110: 1573-1580.

31. Yoshizawa T, Handa Y, Uematsu Y, et al, 1997 Mice lacking the vitamin $\mathrm{D}$ receptor exhibit impaired bone formation, uterine hypoplasia and growth retardation after weaning. Nat Genet 16: 391-396.

32. Kinuta K, Tanaka H, Moriwake T, Aya K, Kato S, Seino Y, 2000 Vitamin D is an important factor in estrogen biosynthesis of both female and male gonads. Endocrinology 141: 1317-1324.

33. Johnson LE, DeLuca HF, 2001 Vitamin D receptor null mutant mice fed high levels of calcium are fertile. J Nutr 131: 1787-1791.

34. Sun W, Xie H, Ji J, Zhou X, Goltzman D, Miao D, 2010 Defective female reproductive function in $1,25(\mathrm{OH}) 2 \mathrm{D}-$ deficient mice results from indirect effect mediated by extracellular calcium and/or phosphorus. Am J Physiol Endocrinol Metab 299: E928-935.

35. Panda DK, Miao D, Bolivar I, et al, 2004 Inactivation of the 25-hydroxyvitamin D 1alpha-hydroxylase and vitamin $\mathrm{D}$ receptor demonstrates independent and interdependent effects of calcium and vitamin D on skeletal and mineral homeostasis. J Biol Chem 279: 16754-16766.

36. Kwiecinksi GG, Petrie GI, DeLuca HF, 1989 1,25-Dihydroxyvitamin D3 restores fertility of vitamin D-deficient female rats. Am J Physiol 256: E483-487.

37. Abbas MA, Taha MO, Disi AM, Shomaf M, 2013 Re- gression of endometrial implants treated with vitamin D3 in a rat model of endometriosis. Eur J Pharmacol 715: 72-75

38. Yildirim B, Guler T, Akbulut M, Oztekin O, Sariiz G, 2014 1-alpha,25-dihydroxyvitamin D3 regresses endometriotic implants in rats by inhibiting neovascularization and altering regulation of matrix metalloproteinase. Postgrad Med 126: 104-110.

39. Mariani M, Vigano P, Gentilini D, et al, 2012 The selective vitamin D receptor agonist, elocalcitol, reduces endometriosis development in a mouse model by inhibiting peritoneal inflammation. Hum Reprod 27: 2010-2019

40. Tesic D, Hawes JE, Zosky GR, Wyrwoll CS, 2015 Vitamin D Deficiency in BALB/c Mouse Pregnancy Increases Placental Transfer of Glucocorticoids. Endocrinology 156: 3673-3679.

41. Azziz R, Woods KS, Reyna R, Key TJ, Knochenhauer ES, Yildiz BO, 2004 The prevalence and features of the polycystic ovary syndrome in an unselected population. J Clin Endocrinol Metab 89: 2745-2749.

42. Goodarzi MO, Dumesic DA, Chazenbalk G, Azziz R, 2011 Polycystic ovary syndrome: etiology, pathogenesis and diagnosis. Nat Rev Endocrinol 7: 219-231.

43. Pittas AG, Lau J, Hu FB, Dawson-Hughes B, 2007 The role of vitamin $\mathrm{D}$ and calcium in type 2 diabetes. A systematic review and meta-analysis. J Clin Endocrinol Metab 92: 2017-2029.

44. Maestro B, Davila N, Carranza MC, Calle C, 2003 Identification of a Vitamin D response element in the human insulin receptor gene promoter. J Steroid Biochem Mol Biol 84: 223-230.

45. Maestro B, Molero S, Bajo S, Davila N, Calle C, 2002 Transcriptional activation of the human insulin receptor gene by 1,25-dihydroxyvitamin $\mathrm{D}(3)$. Cell Biochem Funct 20: 227-232.

46. Mahmoudi T, 2009 Genetic variation in the vitamin D receptor and polycystic ovary syndrome risk. Fertil Steril 92: 1381-1383.

47. Mahmoudi T, Majidzadeh AK, Farahani H, et al, 2015 Association of vitamin D receptor gene variants with polycystic ovary syndrome: A case control study. Int J Reprod Biomed (Yazd) 13: 793-800.

48. Jedrzejuk D, Laczmanski L, Milewicz A, et al, 2015 Classic PCOS phenotype is not associated with deficiency of endogenous vitamin D and VDR gene polymorphisms rs731236 (TaqI), rs7975232 (ApaI), rs1544410 (BsmI), rs 10735810 (FokI): a case-control study of lower Silesian women. Gynecol Endocrinol 31: 976-979.

49. Dasgupta S, Dutta J, Annamaneni S, Kudugunti N, Battini MR, 2015 Association of vitamin D receptor gene polymorphisms with polycystic ovary syndrome among Indian women. Indian J Med Res 142: 276-285.

50. Ranjzad F, Mahmoudi T, Irani Shemirani A, et al, 2012 A common variant in the adiponectin gene and polycystic 
ovary syndrome risk. Mol Biol Rep 39: 2313-2319.

51. Zadeh-Vakili A, Ramezani Tehrani F, Daneshpour MS, Zarkesh M, Saadat N, Azizi F, 2013 Genetic polymorphism of vitamin $\mathrm{D}$ receptor gene affects the phenotype of PCOS. Gene 515: 193-196.

52. Wehr E, Trummer O, Giuliani A, Gruber HJ, Pieber TR, Obermayer-Pietsch B, 2011 Vitamin D-associated polymorphisms are related to insulin resistance and vitamin D deficiency in polycystic ovary syndrome. Eur J Endocrinol 164: 741-749.

53. Ranjzad F, Mahban A, Shemirani AI, et al, 2011 Influence of gene variants related to calcium homeostasis on biochemical parameters of women with polycystic ovary syndrome. J Assist Reprod Genet 28: 225-232.

54. Panidis D, Balaris C, Farmakiotis D, et al, 2005 Serum parathyroid hormone concentrations are increased in women with polycystic ovary syndrome. Clin Chem 51: 1691-1697.

55. Mahmoudi T, Gourabi H, Ashrafi M, Yazdi RS, Ezabadi Z, 2010 Calciotropic hormones, insulin resistance, and the polycystic ovary syndrome. Fertil Steril 93: 12081214.

56. Ngo DT, Chan WP, Rajendran S, et al, 2011 Determinants of insulin responsiveness in young women: Impact of polycystic ovarian syndrome, nitric oxide, and vitamin D. Nitric oxide 25: 326-330.

57. Sadhir M, Kansra AR, Menon S, 2015 Vitamin D Deficiency among Adolescent Females with Polycystic Ovary Syndrome. J Pediatr Adolesc Gynecol 28: 378381 .

58. Joham AE, Teede HJ, Cassar S, et al, 2015 Vitamin D in polycystic ovary syndrome: Relationship to obesity and insulin resistance. Mol Nutr Food Res 60: 110-118.

59. Muscogiuri G, Policola C, Prioletta A, et al, 2012 Low levels of 25(OH)D and insulin-resistance: 2 unrelated features or a cause-effect in PCOS? Clinl Nutr 31: 476-480.

60. Hahn S, Haselhorst U, Tan S, et al, 2006 Low serum 25-hydroxyvitamin $\mathrm{D}$ concentrations are associated with insulin resistance and obesity in women with polycystic ovary syndrome. Exp Clin Endocrinol Diabetes 114: 577-583.

61. Sahin S, Eroglu M, Selcuk S, et al, 2014 Intrinsic factors rather than vitamin $\mathrm{D}$ deficiency are related to insulin resistance in lean women with polycystic ovary syndrome. Eur Rev Med Pharmacol Sci 18: 2851-2856.

62. Ganie MA, Marwaha RK, Nisar S, et al, 2016 Impact of hypovitaminosis D on clinical, hormonal and insulin sensitivity parameters in normal body mass index polycystic ovary syndrome women. J Obstet Gynaecol 36: 508-512.

63. Yildizhan R, Kurdoglu M, Adali E, et al, 2009 Serum 25-hydroxyvitamin D concentrations in obese and non-obese women with polycystic ovary syndrome. Arch Gynecol Obstet 280: 559-563.

64. Wehr E, Pilz S, Schweighofer N, et al, 2009 Associa- tion of hypovitaminosis D with metabolic disturbances in polycystic ovary syndrome. Eur J Endocrinol 161: 575-582.

65. Li HW, Brereton RE, Anderson RA, Wallace AM, Ho CK, 2011 Vitamin D deficiency is common and associated with metabolic risk factors in patients with polycystic ovary syndrome. Metabolism 60: 1475-1481.

66. Patra SK, Nasrat H, Goswami B, Jain A, 2012 Vitamin $\mathrm{D}$ as a predictor of insulin resistance in polycystic ovarian syndrome. Diabetes Metab Syndr 6: 146-149.

67. Mishra S, Das AK, Das S, 2016 Hypovitaminosis D and Associated Cardiometabolic Risk in Women with PCOS. J Clin Diagn Res 10: Bc01-4.

68. Savastano S, Valentino R, Di Somma C, et al, 2011 Serum 25-Hydroxyvitamin D Levels, phosphoprotein enriched in diabetes gene product (PED/PEA-15) and leptin-to-adiponectin ratio in women with PCOS. Nutr Metab (Lond) 8: 84.

69. Pal L, Zhang H, Williams J, et al, 2016 Vitamin D Status Relates to Reproductive Outcome in Women With Polycystic Ovary Syndrome: Secondary Analysis of a Multicenter Randomized Controlled Trial. J Clin Endocrinol Metab 101: 3027-3035.

70. Ott J, Wattar L, Kurz C, et al, 2012 Parameters for calcium metabolism in women with polycystic ovary syndrome who undergo clomiphene citrate stimulation: a prospective cohort study. Eur J Endocrinol 166: 897902.

71. Thys-Jacobs S, Donovan D, Papadopoulos A, Sarrel P, Bilezikian JP, 1999 Vitamin D and calcium dysregulation in the polycystic ovarian syndrome. Steroids 64 : 430-435.

72. Rashidi B, Haghollahi F, Shariat M, Zayerii F, 2009 The effects of calcium-vitamin D and metformin on polycystic ovary syndrome: a pilot study. Taiwan J Obstet Gynecol 48: 142-147.

73. Firouzabadi R, Aflatoonian A, Modarresi S, Sekhavat L, MohammadTaheri S, 2012 Therapeutic effects of calcium \& vitamin D supplementation in women with PCOS. Complement Ther Clin Pract 18: 85-88.

74. Asadi M, Matin N, Frootan M, Mohamadpour J, Qorbani M, Tanha FD, 2014 Vitamin D improves endometrial thickness in PCOS women who need intrauterine insemination: a randomized double-blind placebo-controlled trial. Arch Gynecol Obstet 289: 865-870.

75. Wehr E, Pieber TR, Obermayer-Pietsch B, 2011 Effect of vitamin D3 treatment on glucose metabolism and menstrual frequency in polycystic ovary syndrome women: a pilot study. J Endocrinol Invest 34: 757-763.

76. Selimoglu H, Duran C, Kiyici S, et al, 2010 The effect of vitamin D replacement therapy on insulin resistance and androgen levels in women with polycystic ovary syndrome. J Endocrinol Invest 33: 234-238.

77. Pal L, Berry A, Coraluzzi L, et al, 2012 Therapeutic implications of vitamin D and calcium in overweight women with polycystic ovary syndrome. Gynecol 
Endocrinol 28: 965-968.

78. Razavi M, Jamilian M, Karamali M, Bahmani F, Aghadavod E, Asemi Z, 2016 The Effects of Vitamin D-KCalcium Co-Supplementation on Endocrine, Inflammation, and Oxidative Stress Biomarkers in Vitamin D-Deficient Women with Polycystic Ovary Syndrome: A Randomized, Double-Blind, Placebo-Controlled Trial. Horm Metab Res 48: 446-451.

79. Kotsa K, Yavropoulou MP, Anastasiou O, Yovos JG, 2009 Role of vitamin D treatment in glucose metabolism in polycystic ovary syndrome. Fertil Steril 92: 1053-1058.

80. Rahimi-Ardabili H, Pourghassem Gargari B, Farzadi L, 2013 Effects of vitamin D on cardiovascular disease risk factors in polycystic ovary syndrome women with vitamin D deficiency. J Endocrinol Invest 36: 28-32.

81. Raja-Khan N, Shah J, Stetter CM, et al, 2014 High-dose vitamin D supplementation and measures of insulin sensitivity in polycystic ovary syndrome: a randomized, controlled pilot trial. Fertil Steril 101: 1740-1746.

82. Ardabili HR, Gargari BP, Farzadi L, 2012 Vitamin D supplementation has no effect on insulin resistance assessment in women with polycystic ovary syndrome and vitamin D deficiency. Nutr Res 32: 195-201.

83. Asemi Z, Foroozanfard F, Hashemi T, Bahmani F, Jamilian M, Esmaillzadeh A, 2015 Calcium plus vitamin D supplementation affects glucose metabolism and lipid concentrations in overweight and obese vitamin D deficient women with polycystic ovary syndrome. Clin Nutr 34: 586-592.

84. Garg G, Kachhawa G, Ramot R, et al, 2015 Effect of vitamin D supplementation on insulin kinetics and cardiovascular risk factors in polycystic ovarian syndrome: a pilot study. Endocr Connect 4: 108-116.

85. He C, Lin Z, Robb SW, Ezeamama AE, 2015 Serum Vitamin D Levels and Polycystic Ovary syndrome: A Systematic Review and Meta-Analysis. Nutrients 7: 4555-4577.

86. Jia XZ, Wang YM, Zhang N, et al, 2015 Effect of vitamin $\mathrm{D}$ on clinical and biochemical parameters in polycystic ovary syndrome women: A meta-analysis. J Obstet Gynaecol Res 41: 1791-1802.

87. Fang F, Ni K, Cai Y, Shang J, Zhang X, Xiong C, 2017 Effect of vitamin D supplementation on polycystic ovary syndrome: A systematic review and meta-analysis of randomized controlled trials. Complement Ther Clin Pract 26: 53-60.

88. Xue Y, Xu P, Xue K, et al, 2017 Effect of vitamin D on biochemical parameters in polycystic ovary syndrome women: a meta-analysis. Arch Gynecol Obstet 295: 487-496.

89. Diamanti-Kandarakis E, Katsikis I, Piperi C, et al, 2008 Increased serum advanced glycation end-products is a distinct finding in lean women with polycystic ovary syndrome (PCOS). Clin Endocrinol (Oxf) 69: 634-641.

90. Merhi Z, 2014 Advanced glycation end products and their relevance in female reproduction. Hum Reprod 29: 135-145

91. Kalea AZ, Schmidt AM, Hudson BI, 2009 RAGE: a novel biological and genetic marker for vascular disease. Clin Sci (Lond) 116: 621-637.

92. Irani M, Minkoff H, Seifer DB, Merhi Z, 2014 Vitamin D increases serum levels of the soluble receptor for advanced glycation end products in women with PCOS. J Clin Endocrinol Metab 99: E886-890.

93. Irani M, Seifer DB, Grazi RV, et al, 2015 Vitamin D Supplementation decreases TGF-beta1 bioavailability in PCOS: A randomized placebo-controlled trial. J Clin Endocrinol Metab 100: 4307-4314.

94. Raja-Khan N, Kunselman AR, Demers LM, Ewens $\mathrm{KG}$, Spielman RS, Legro RS, 2010 A variant in the fibrillin-3 gene is associated with TGF-beta and inhibin B levels in women with polycystic ovary syndrome. Fertil Steril 94: 2916-2919.

95. Tal R, Seifer DB, Shohat-Tal A, Grazi RV, Malter HE, 2013 Transforming growth factor-betal and its receptor soluble endoglin are altered in polycystic ovary syndrome during controlled ovarian stimulation. Fertil Steril 100: 538-543.

96. Karras SN, Anagnostis P, Naughton D, Annweiler C, Petroczi A, Goulis DG, 2015 Vitamin D during pregnancy: why observational studies suggest deficiency and interventional studies show no improvement in clinical outcomes? A narrative review. J Endocrinol Invest 38: 1265-1275.

97. Bulun SE, 2009 Endometriosis. N Engl J Med 360: 268-279.

98. Vigano P, Lattuada D, Mangioni S, et al, 2006 Cycling and early pregnant endometrium as a site of regulated expression of the vitamin D system. J Mol Endocrinol 36: 415-424.

99. Hartwell D, Rodbro P, Jensen SB, Thomsen K, Christiansen C, 1990 Vitamin D metabolites--relation to age, menopause and endometriosis. Scand J Clin Lab Invest 50: 115-121.

100. Agic A, Xu H, Altgassen C, et al, 2007 Relative expression of 1,25-dihydroxyvitamin D3 receptor, vitamin D 1 alpha-hydroxylase, vitamin D 24-hydroxylase, and vitamin D 25-hydroxylase in endometriosis and gynecologic cancers. Repr Sci 14: 486-497.

101. Harris HR, Chavarro JE, Malspeis S, Willett WC, Missmer SA, 2013 Dairy-food, calcium, magnesium, and vitamin D intake and endometriosis: a prospective cohort study. Am J Epidemiol 177: 420-430.

102. Ciavattini A, Serri M, Delli Carpini G, Morini S, Clemente N, 2017 Ovarian endometriosis and vitamin D serum levels. Gynecol Endocrinol 33: 164-167.

103. Somigliana E, Panina-Bordignon P, Murone S, Di Lucia P, Vercellini P, Vigano P, 2007 Vitamin D reserve is higher in women with endometriosis. Hum Reprod 22: 2273-2278.

104. Ferrero S, Gillott DJ, Anserini P, et al, 2005 Vitamin 
D binding protein in endometriosis. J Soc Gynecol Investig 12: 272-277.

105. Borkowski J, Gmyrek GB, Madej JP, et al, 2008 Serum and peritoneal evaluation of vitamin D-binding protein in women with endometriosis. Postepy Hig Med Dosw (Online) 62: 103-109.

106. Cho S, Choi YS, Yim SY, et al, 2012 Urinary vitamin $\mathrm{D}$-binding protein is elevated in patients with endometriosis. Hum Reprod 27: 515-522.

107. Hwang JH, Wang T, Lee KS, Joo JK, Lee HG, 2013 Vitamin D binding protein plays an important role in the progression of endometriosis. Int J Mol Med 32: 1394-1400.

108. Faserl K, Golderer G, Kremser L, et al, 2011 Polymorphism in vitamin D-binding protein as a genetic risk factor in the pathogenesis of endometriosis. J Clin Endocrinol Metab 96: E233-241

109. Vilarino FL, Bianco B, Lerner TG, et al, 2011 Analysis of vitamin D receptor gene polymorphisms in women with and without endometriosis. Hum Immunol 72: 359-363.

110. Ozkan S, Jindal S, Greenseid K, Shu J, Zeitlian G, Hickmon C, et al, 2010 Replete vitamin D stores predict reproductive success following in vitro fertilization. Fertil Steril 94: 1314-1319.

111.Rudick B, Ingles S, Chung K, Stanczyk F, Paulson R, Bendikson K, 2012 Characterizing the influence of vitamin D levels on IVF outcomes. Hum Reprod 27: 3321-3327.

112. Rudick BJ, Ingles SA, Chung K, Stanczyk FZ, Paulson RJ, Bendikson KA, 2014 Influence of vitamin D levels on in vitro fertilization outcomes in donor-recipient cycles. Fertil Steril 101: 447-452.

113. Garbedian K, Boggild M, Moody J, Liu KE, 2013 Effect of vitamin D status on clinical pregnancy rates following in vitro fertilization. CMAJ open 1: E77-82.

114. Paffoni A, Ferrari S, Vigano P, et al, 2014 Vitamin D deficiency and infertility: insights from in vitro fertilization cycles. J Clin Endocrinol Metab 99: E2372-2376.

115. Farzadi L, Khayatzadeh Bidgoli H, Chojazadeh et al, 2015 Correlation between follicular fluid $25-\mathrm{OH}$ vitamin D and assisted reproductive outcomes. Iran J Reprod Med 13: 361-366.

116. Polyzos NP, Anckaert E, Guzman L, et al, 2014 Vitamin $\mathrm{D}$ deficiency and pregnancy rates in women undergoing single embryo, blastocyst stage, transfer (SET) for IVF/ICSI. Hum Reprod 29: 2032-2040.

117. Anifandis GM, Dafopoulos K, Messini CI, et al, 2010 Prognostic value of follicular fluid 25-OH vitamin D and glucose levels in the IVF outcome. Reprod Biol Endocrinol 8: 91.
118. Aleyasin A, Hosseini MA, Mahdavi A, et al, 2011 Predictive value of the level of vitamin D in follicular fluid on the outcome of assisted reproductive technology. Eur J Obstet Gynecol Reprod Biol 159: 132-137.

119. Firouzabadi RD, Rahmani E, Rahsepar M, Firouzabadi MM, 2014 Value of follicular fluid vitamin D in predicting the pregnancy rate in an IVF program. Arch Gynecol Obstet 289: 201-206.

120. Franasiak JM, Molinaro TA, Dubell EK, et al, 2015 Vitamin D levels do not affect IVF outcomes following the transfer of euploid blastocysts. Am J Obstet Gynecol 212: 315.e1-6.

121. van de Vijver A, Drakopoulos P, Van Landuyt L, et al, 2016 Vitamin D deficiency and pregnancy rates following frozen-thawed embryo transfer: a prospective cohort study. Hum Reprod 31: 1749-1754.

122. Fabris A, Pacheco A, Cruz M, Puente JM, Fatemi H, Garcia-Velasco JA, 2014 Impact of circulating levels of total and bioavailable serum vitamin D on pregnancy rate in egg donation recipients. Fertil Steril 102: 1608-1612.

123. Aflatoonian A, Arabjahvani F, Eftekhar M, Sayadi M, 2014 Effect of vitamin D insufficiency treatment on fertility outcomes in frozen-thawed embryo transfer cycles: A randomized clinical trial. Iran J Reprod Med 12: 595-600.

124. Lv SS, Wang JY, Wang XQ, Wang Y, Xu Y, 2016 Serum vitamin $\mathrm{D}$ status and in vitro fertilization outcomes: a systematic review and meta-analysis. Arch Gynecol Obstet 293: 1339-1345.

125. Holick MF, Binkley NC, Bischoff-Ferrari HA, et al, 2011 Evaluation, treatment, and prevention of vitamin D deficiency: an Endocrine Society clinical practice guideline. J Clin Endocrinol Metab 96: 1911-1930.

126. Rosen CJ, Abrams SA, Aloia JF, et al, 2012 IOM committee members respond to Endocrine Society vitamin D guideline. J Clin Endocrinol Metab 97: 1146-1152.

127. Heaney RP, Recker RR, Grote J, Horst RL, Armas LA, 2011 Vitamin $\mathrm{D}(3)$ is more potent than vitamin $\mathrm{D}(2)$ in humans. J Clin Endocrinol Metab 96: E447-452.

128. Trang HM, Cole DE, Rubin LA, Pierratos A, Siu S, Vieth R, 1998 Evidence that vitamin D3 increases serum 25-hydroxyvitamin D more efficiently than does vitamin D2. Am J Clin Nutr 68: 854-858.

129. Armas LA, Hollis BW, Heaney RP, 2004 Vitamin D2 is much less effective than vitamin D3 in humans. J Clin Endocrinol Metab 89: 5387-5391.

130. Binkley N, Gemar D, Engelke J, et al, 2011 Evaluation of ergocalciferol or cholecalciferol dosing, 1,600 IU daily or 50,000 IU monthly in older adults. J Clin Endocrinol Metab 96: 981-988. 